\title{
Pulmonary arterial development during childhood: branching pattern and structure
}

\author{
ALISON HISLOP and LYNNE REID \\ Department of Experimental Pathology, Cardiothoracic Institute, Brompton Hospital, London S.W.3
}

In lungs from 18 children aged between birth and 11 years the development of the branching pattern and structure of the pulmonary arteries, particularly the intralobular and intra-acinar, has been quantitatively analysed after injection with a radio-opaque medium. Up to 18 months of age as new alveolar ducts appear conventional arterial branches develop within the acinus: supernumerary arteries increase in number up to 8 years as new alveoli form. Both types increase in size with age.

After birth there is an immediate drop in wall thickness of the vessels below $200 \mu \mathrm{m}$ diameter while the larger vessels take up to 4 months to fall to adult thickness, suggesting two types of response-one dilatation, the other a growth rate change of the muscle cells. During childhood muscle cell formation in the intra-acinar arteries lags behind increase in artery size so that during childhood few muscular arteries are found within the acinus. The functional significance of these changes is discussed.

In the pre-acinar region of the lung the branching pattern of arteries and airways is complete by the sixteenth week of intrauterine life and their structural type is already established (Bucher and Reid, 1961 ; Hislop and Reid, 1972a). In this region further growth, even after birth, is only in dimensions.

At birth the alveolar region is represented by primitive air spaces described by Boyden (1965) as 'saccules', counts of which suggest that only about 20 million are then present, but by eight years alveoli have appeared and multiplied to the adult figure of 300 million (Dunnill, 1962 ; Davies and Reid, 1970). During early childhood the acinus grows rapidly by the budding of new alveoli from respiratory bronchioli, alveolar ducts, and more distal air spaces (Boyden and Tompsett, 1965) and later there is an increase in alveolar size, which continues up to adulthood (Davies and Reid, 1970). In the intra-acinar region new arteries develop and it is with these that the present study is mainly concerned.

Using a Vultex moulage cast of the adult acinus, Pump (1961) showed that proximal to the alveolar ducts the arteries ran with airways as in the preacinar region, but at the alveolar duct level they broke up into a network of pre-capillaries. Reid and Heard (1963) noted that arteries accompanying the respiratory bronchioli and alveolar ducts gave off many branches. These were described by Elliott and Reid (1965) as intra-acinar super- numerary arteries supplying the alveoli directly. These extra arteries they found also throughout the pre-acinar region. Boyden (1965), using a waxplate reconstruction, described extra branches in the intra-acinar region of a 37-day-old infant. Since there has been no previous report of the branching pattern of the arteries within the acinus during the growing period of childhood a study was undertaken using serial reconstruction.

Previous studies on the structure of the pulmonary arteries during childhood have been confined to those on wall thickness soon after birth. Naeye (1961), using planimetry, reported a decrease in arterial muscle wall thickness in early childhood associated with a reduction in the number of muscle cells. Wagenvoort and Wagenvoort (1965) found that this drop was complete by 18 months when the wall was as thick as in the adult. Using injected specimens for the first time, Davies and Reid (1970) showed that the adult wall thickness was reached by 4 months and that during childhood muscle did not extend into such small arteries as it does in either the fetus or the adult. This interesting feature has been further analysed in the present study.

\section{MATERIAL AND METHODS}

Normal child lungs are difficult to obtain and over a period of five years only 18 specimens were collected; the lungs were considered normal because the children had died accidentally. 
The pulmonary arteries were injected with a radioopaque medium at a pressure of $100 \mathrm{~cm}$ water and a temperature of $60^{\circ} \mathrm{C}$ (Hislop and Reid, 1970 ; Hislop, 1971). Radiographs of the specimens were used to study the overall pattern of arterial branching and for measurement of the pre-acinar arteries. The intralobular branching pattern was traced by study of serial sections cut from a block of tissue taken from the diaphragmatic surface of the posterior basal segment of the left lung and that included an axial pathway. Additional blocks were taken for quantitative studies on the arteries, including estimation of percentage wall thickness and of extension of muscle into small arteries and into the acinus, together with measurement of the number and size of intra-acinar arteries and 'population counts'. These methods have already been described in detail (Davies and Reid, 1970; Hislop and Reid, 1972a).

\section{RESULTS}

Observation of the arteriograms confirmed the findings of Davies and Reid (1970) that the main branching pattern in childhood is similar to that of the fetus and newborn. Rapid multiplication of small vessels in the first 10 months after birth produces a dense background haze that blurs the outline of the main vessels. Measurements of the main pathways showed trends of growth similar to those seen in the fetus, with a linear relation between the increase in arterial diameter and length. The rate of increase was greater during the first 18 months of life.

INTRA-ACINAR ARTERIAL BRANCHING PATTERN AND DIMENSION At birth the acinus-defined as the region beyond the terminal bronchiolus-is small and simple. In one case at birth there were four generations of respiratory bronchioli and two of alveolar ducts before the saccules that at this stage made up the alveolar region (Boyden, 1965). Conventional arteries accompanied the airway branches and, in addition, there were supernumerary arteries fewer in relation to the conventional arteries than in the pre-acinar region (Hislop and Reid, 1972a).

The branching pattern of arteries and airways within a lobule and in the immediately prelobular region was also traced in six children aged 3 days, 4 and 18 months, and 5, 10, and 11 years, to illustrate the changes with age. Figures 1 and 2 are diagrammatic representations of the branching pattern and diameter of the arteries at 4 months and 5 years of age.



FIG. 1. Pre- and intra-lobular arteries in a child of 4 months. The horizontal axis represents the last $5 \cdot 1 \mathrm{~mm}$ of an axial pathway: each branch is seen as a vertical line whose height represents diameter. The acinus is small with only five conventional and six supernumerary arteries (cf Fig. 2).

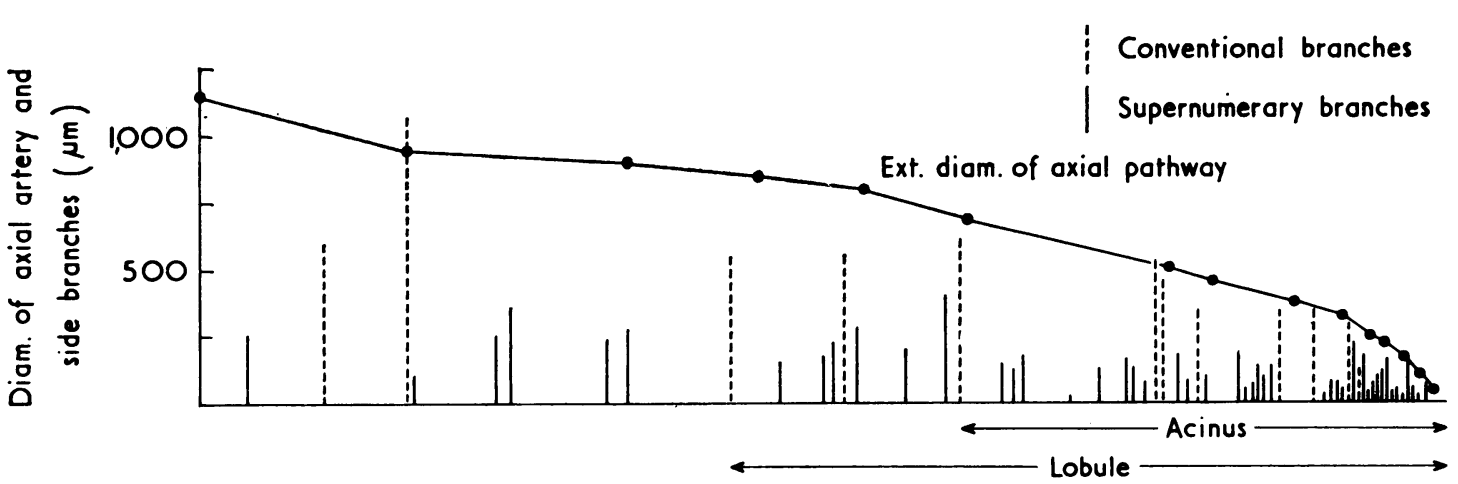

FIG. 2. Pre-and intra-lobular arteries in a child of 5 years. The horizontal axis represents the last $12.6 \mathrm{~mm}$ of an axial pathway. Each branch is seen as a vertical line whose height represents diameter (cf Fig. 1). The length of the acinus and lobule has increased and also the number of conventional and supernumerary arteries, particularly the latter. All vessels have increased in size. 
The length of the acinus generally increased with age while the pre-acinar intralobular region was sometimes longer and sometimes shorter than the acinus. The number of terminal and respiratory bronchioli branching from the axial airway varied but showed no trend related to age. There was an increase in the number of alveolar duct generations up to the age of 18 months when the adult pattern was present (Elliott, 1964). There was considerable variation between acini.

Arteries develop alongside the new airways so that the number of conventional and supernumerary arteries also increased with age, particularly the latter, and the ratio of supernumerary to conventional arteries increased to reach the adult value by 5 years. This ratio is higher than in the pre-acinar region.

The axial artery showed an increase in diameter with age. At all ages the conventional arteries were smaller than the parent axial vessel at their point of origin ; they generally decreased in diameter towards the periphery. Their mean diameter increased with age as did the mean diameter of the supernumerary arteries. The latter varied in size but were always smaller than adjacent conventional arteries.

ALVEOLAR AND ARTERY NUMBER The development of the arteries and alveoli after birth has been studied using random sections in which the number of small vessels and alveoli in a square centimetre of respiratory tissue has been counted (Hislop, 1971).

During fetal life, the total number of vessels is low ; this increases gradually up to 18 months of age and then falls (Table I). The rapid increase in number must be related to the rapid multiplication of alveoli up to the age of 4 years (Dunnill, 1962). The drop in arteries per unit area at 5 and
T A B LE I

ALVEOLAR AND INTRA-ACINAR ARTERIAL NUMBER DURING CHILDHOOD

\begin{tabular}{|c|c|c|c|}
\hline Age & \multicolumn{2}{|c|}{$\begin{array}{l}\text { Alveoli } \quad \text { Arteries } \\
\text { (per square centimetre) }\end{array}$} & $\begin{array}{c}\text { Ratio } \\
\text { Alveoli/Arteries }\end{array}$ \\
\hline $\begin{array}{l}\text { Birth } \\
3 \text { days } \\
4 \mathrm{mth} \\
10 \mathrm{mth} \\
18 \mathrm{mth} \\
3 \mathrm{yr} \\
4 \mathrm{yr} \\
5 \mathrm{yr} \\
10 \mathrm{yr}\end{array}$ & $\begin{array}{r}8,227 \\
4,689 \\
11,315 \\
12,418 \\
10,477 \\
12,903 \\
9,529 \\
9,123 \\
8,580\end{array}$ & $\begin{array}{r}58 \\
188 \\
116 \\
287 \\
364 \\
250 \\
233 \\
195 \\
179\end{array}$ & $\begin{array}{l}141 \\
25 \\
97 \cdot 5 \\
43 \cdot 26 \\
28 \cdot 7 \\
51 \cdot 6 \\
40 \cdot 8 \\
46 \cdot 8 \\
47 \cdot 9\end{array}$ \\
\hline
\end{tabular}

10 years is due to an increase in the size of alveoli (Davies and Reid, 1970) resulting in the separation of the arteries.

Assuming that all cases have been inflated to the same degree, alveolar size can be assessed from the number of alveoli in a square centimetre. At birth the air spaces are relatively large (Table I), being in the form of simple saccules (Boyden, 1965). By 4 months the alveoli are much smaller, due to budding of new alveoli from the airways and within the saccules. Between 4 months and 3 years the alveoli remain small since this is the period of rapid multiplication, while from 4 to 10 years as multiplication slows the alveoli gradually increase in size.

The arteries grow and multiply as the alveoli develop. Although the ratio of alveoli to arteries is similar throughout childhood the number of arteries per unit area falls as the alveoli increase in size.

\section{STRUCTURE OF ARTERIES}

Percentage wall thickness During fetal life and at birth wall thickness is greater than in childhood, giving a mean percentage wall thickness in arteries over $200 \mu \mathrm{m}$ diameter of 4 to $5 \%$ (Hislop

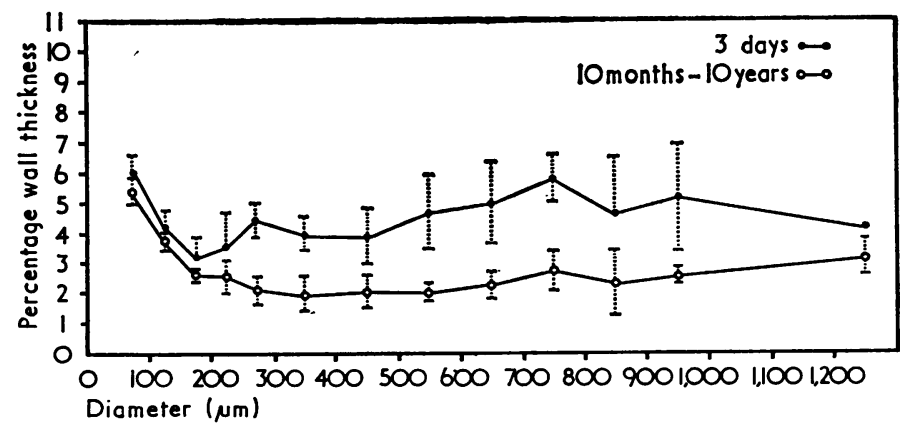

FIG. 3. Arterial wall thickness related to external diameter in a 3-dayold infant and in children aged 10 months to 10 years. The mean and standard deviation for each size range is shown. 
and Reid, 1972a). In the present series all children over 4 months of age showed the adult pattern of a percentage wall thickness of 1 to 3 in larger vessels and a gradual increase in percentage wall thickness up to 6 in vessels less than $200 \mu \mathrm{m}$ in external diameter (Elliott, 1964). Figure 3 shows the mean percentage wall thickness of children aged 10 months to 10 years and that of a child aged 3 days. In the last, while the arteries over $200 \mu \mathrm{m}$ external diameter still had a percentage wall thickness in the range of the fetal ages, for



FIG. 4. Population counts of muscular (m), partially muscular (p.m), and non-muscular (n.m) arteries in a 3-day-old infant, an 18-month and a 10-year-old child. Muscular or partially muscular structure is not seen in such small arteries at 18 months. those below $200 \mu \mathrm{m}$ the adult range had been reached. Thinning of the small vessels had been immediate, probably due to dilatation. Only after 4 months had the larger vessels lost their fetal wall thickness.

Population counts Population counts of the vessels in the acinar region were made on nine of the children. Figure 4 shows three representative cases and the results for all are given in Table II.

T A B L E I I

STRUCTURE AND SIZE $(\mu \mathrm{m})$ OF SMALL VESSELS DURING CHILDHOOD

\begin{tabular}{c|c|c|c}
\hline Age & $\begin{array}{c}\text { Largest } \\
\text { Non-muscular }\end{array}$ & $\begin{array}{c}\text { Range of } \\
\text { Partially } \\
\text { Muscular }\end{array}$ & $\begin{array}{c}\text { Smallest } \\
\text { Muscular }\end{array}$ \\
\hline 3 days & 152 & $40-180$ & 120 \\
4 mth & 130 & $40-170$ & 75 \\
10 mth & 125 & $55-220$ & 112 \\
18 mth & 245 & $100-300$ & 185 \\
3 yr & 126 & $52-295$ & 77 \\
4 yr & 160 & $50-320$ & 135 \\
5 yr & 202 & $50-370$ & 155 \\
$10 \mathrm{yr}$ & 87 & $23-195$ & 94 \\
11 yr & 160 & $50-320$ & 148 \\
\hline
\end{tabular}

At 3 days the distribution by size of the three structural artery types-muscular, partially muscular, and non-muscular-was similar to that seen at birth with partially muscular and non-muscular arteries as large as $180 \mu \mathrm{m}$ and $150 \mu \mathrm{m}$ respectively. Below $40 \mu \mathrm{m}$ all arteries were non-muscular in structure. By 4 months arteries had increased in size. Since the population count was similar to that at birth new muscle growth must have been keeping pace with increase in artery size. By 18 months a lag is apparent-the largest partially muscular artery was $300 \mu \mathrm{m}$, the largest nonmuscular vessels $245 \mu \mathrm{m}$. Wholly muscular arteries were not found smaller than $185 \mu \mathrm{m}$ diameter.

A distribution of muscle similar to that in the 18-month-old child was found in those aged 3, 4, 5 , and 11 years. In the case of 10 years, however, the pattern of distribution was similar to that seen in the adult (Elliott, 1964).

Arteries with airways Artery size and structure can be analysed by relating the artery to an identifiable airway either by serial reconstruction or by using one of the structures recognizable in a single section-terminal and respiratory bronchioli, alveolar ducts, and alveoli. The external diameter of the arteries accompanying such airways is shown in Table III. As in the fetus (Hislop and Reid, 1972a), there was a reduction in mean diameter towards the periphery of the lung but for each type of airway there is a large range of artery size due to the number of generations. At all levels there was an increase in diameter with age. This 
increase was relatively greater in arteries with the more proximal airways and faster in the first 18 months.

T A B L E I I I

EXTERNAL DIAMETER ( $\mu \mathrm{m})$ OF PULMONARY ARTERIES ACCOMPANYING INTRALOBULAR AIRWAYS

\begin{tabular}{|c|c|c|c|c|c|}
\hline & Age & $\underset{\text { Bronchiolus }}{\text { Terminal }}$ & $\begin{array}{l}\text { Respiratory } \\
\text { Bronchiolus }\end{array}$ & $\begin{array}{c}\text { Alveolar } \\
\text { Duct }\end{array}$ & Alveoli \\
\hline $\begin{array}{l}3 \text { days } \\
4 \mathrm{mth} \\
10 \mathrm{mth} \\
18 \mathrm{mth} \\
3 \mathrm{yr} \\
4 \mathrm{yr} \\
5 \mathrm{yr} \\
10 \mathrm{yr} \\
11 \mathrm{yr}\end{array}$ & $\begin{array}{l}\text { Mean } \\
\text { Range } \\
\text { Mean } \\
\text { Range } \\
\text { Mean } \\
\text { Range } \\
\text { Mean } \\
\text { Range } \\
\text { Mean } \\
\text { Range } \\
\text { Mean } \\
\text { Range } \\
\text { Mean } \\
\text { Range } \\
\text { Mean } \\
\text { Range } \\
\text { Mean } \\
\text { Range }\end{array}$ & $\begin{array}{l}118 \\
87-175 \\
197 \cdot 3 \\
127-265 \\
301 \\
175-360 \\
321 \cdot 25 \\
250-400 \\
406 \\
320-530 \\
391 \cdot 5 \\
270-550 \\
513 \\
430-600 \\
321 \\
220-430 \\
475 \\
390-750\end{array}$ & $\begin{array}{l}92 \cdot 7 \\
45-145 \\
122 \cdot 3 \\
70-182 \\
184 \\
98-250 \\
206 \cdot 3 \\
125-300 \\
208 \\
112-320 \\
234 \\
120-410 \\
257 \\
80-530 \\
215 \\
105-415 \\
301 \\
162-500\end{array}$ & $\begin{array}{c}65 \\
60-70 \\
86 \cdot 5 \\
70-115 \\
90 \cdot 5 \\
75-145 \\
145 \cdot 7 \\
105-225 \\
144 \\
130-165 \\
140 \\
110-225 \\
151 \\
100-280 \\
188 \\
75-177 \\
175 \\
140-190\end{array}$ & $\begin{array}{c}- \\
33 \cdot 3 \\
25-40 \\
- \\
- \\
- \\
- \\
43 \cdot 4 \\
25-85 \\
46 \\
35-52 \\
-\end{array}$ \\
\hline
\end{tabular}

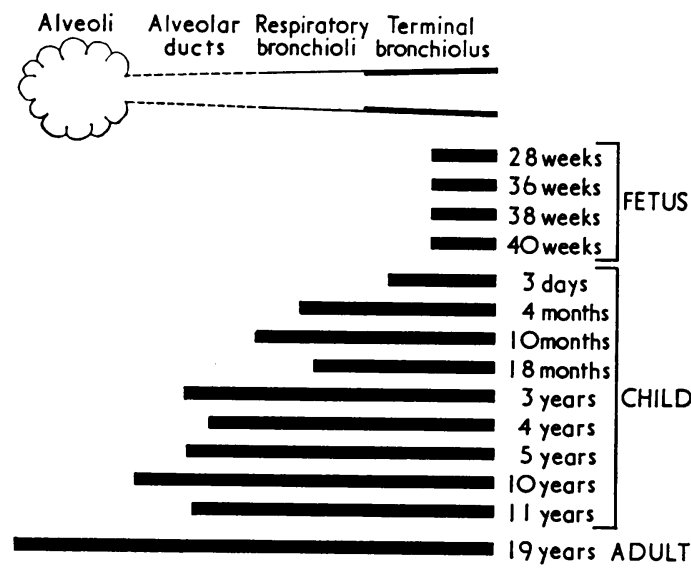

FIG. 5. Diagram illustrating the appearance of muscle in the wall of intra-acinar arteries. In the fetus no muscle is seen within the acinus, with age it extends gradually within the acinus, but even at 11 years not as far as in the adult.

Figure 5 illustrates the extension, throughout childhood, of muscular arteries to the periphery of the acinus. The end of the black line corresponds to the artery diameter at the peak of the partially muscular population so that the majority of the vessels beyond it will be non-muscular. In the fetus and newborn there were no muscular arteries within the acinus. During childhood muscle extended gradually to the periphery but not before 10 years was it present in vessels at alveolar level.
In the adult all the partially muscular vessels as well as many muscular vessels are found in the alveolar wall (Elliott, 1964).

\section{DISCUSSION}

ARTERY BRANCHING PATTERN AND DIMENSION The arterial branching pattern would seem to parallel airway development, pre-acinar being complete by half-way through fetal life (Hislop and Reid, 1972a) and the intra-acinar developing mainly during childhood, along with the alveolar ducts and alveoli as shown in this study. Within the lobule as the alveoli multiply, the ratio of supernumerary to conventional arteries increases and remains higher than in any other region. Here the supernumerary arteries supply the alveoli at the heart of the acinus as well as those at the periphery.

The slowing in the rate of increase in artery length and diameter in the pre- and intra-acinar region at about 18 months of age is probably related to the fact that most of the arterial multiplication is complete by this time.

ARTERY STRUCTURE The proximal artery structure along any pathway is established in adult form by half-way through fetal life (Hislop and Reid, 1972a). Peripheral vessels, however, changed their structure and became more muscular as they increased in size with age, but during childhood muscle growth lags behind increase in arterial diameter so that the intra-acinar pulmonary arterial bed is less muscular in childhood than in the adult. The lag is apparent only after 4 months of age.

The functional significance of this lack of muscle within the arteries of the acinus is not known. The larger non-muscular arteries can be used for gas transfer and probably increase the area available for this. The larger non-muscular and the partially muscular vessels accompany alveolar ducts and respiratory bronchioli but it is thought that there is easy diffusion through the airway walls. Staub (1961) deduced from a study of frozen sections of cat lung that breathing $100 \%$ oxygen there was gas transfer through walls of arterioles up to $200 \mu \mathrm{m}$ external diameter but breathing air, oxygen was taken up only by vessels less than $100 \mu \mathrm{m}$. Children with more non-muscular arteries may be at an advantage in normal or low oxygen tensions.

The absence of muscle may affect the response to hypoxia since several authors have shown that at alveolar level its effect is directly on muscular arteries (von Euler and Liljestrand (1946) in the 
cat ; Burton (1959) in the rabbit; and Kato and Staub (1966) in the cat). This response must be further studied but it is known that increased carbon dioxide or decreased oxygen causes an increase in pulmonary artery pressure (Bergofsky, Lehr, and Fishman, 1962). Constriction may also be conducted to the hilum in some way. Hilton (1959) demonstrated in the cat that changes in the tone of the femoral artery wall could arise by transmission from muscle cell to muscle cell without nervous mediation. It may be that in the child there is less reaction to hypoxia as there are fewer muscle cells in contact with alveolar air.

PERCENTAGE WALL THICKNESS In the fetus there is a relatively high pulmonary arterial wall thickness, a high resistance to blood flow in this system, and a relative right ventricular preponderance in the heart (Hislop and Reid, 1972b). In the adult (Elliott, 1964) and in the child over 4 months, as shown here and by Davies and Reid (1970), the arterial wall thickness is low; the right ventricle of the heart is also relatively smaller. In the 4 months after birth there are changes in the wall thickness of all the vessels. The size of the muscle cells does not change during fetal life and childhood, remaining about $2.5 \mu \mathrm{m}$ in diameter (Hislop, 1971). Naeye (1966) also, using planimetry, considered that there was no change in muscle cell size.

The drop in wall thickness seen in small vessels by the third day after birth is too rapid to be a growth change and probably arises from rapid dilatation. Larroche, Nodot, and Minkowski (1959) also showed a rapid drop in wall thickness of vessels less than $150 \mu \mathrm{m}$ external diameter within 10 days of birth in both premature and full-term babies. Changes in gas tensions may cause the arterial wall to dilate, vascular resistance to fall, and the blood flow to increase (Dawes, Mott, Widdicombe, and Wyatt, 1953). That drugs may also cause vasoconstriction or dilatation of the fetal lung vessels (Adams, 1966) suggests a neurohumoral control. Asphyxia causes vasoconstriction and the increase in oxygen tension of the blood at birth may cause the reduction in resistance. This may be a direct effect or through a mediator such as bradykinin. Melmon, Cline, Hughes, and Nies (1968) found that in lambs bradykinin constricted the umbilical artery and vein and ductus arteriosus but produced dilatation of the pulmonary vasculature. They also found that precursors of this kinin are found circulating in the blood of humans, more in the newborn than the adult. It seems likely that the early dilatation of the muscular vessels smaller than $200 \mu \mathrm{m}$ causes the drop in resistance, since there is some drop in pressure within one hour and it takes only 11 days for the adult levels of resistance to be reached (Rowe and James, 1957).

The drop in arterial wall thickness seen over the first four months of life in vessels over $200 \mu \mathrm{m}$ external diameter would seem to be the effect of change in growth rate, since in this time the wall thickness of any pulmonary artery falls to half its fetal level. While a vessel could considerably increase in diameter and reach adult wall thickness the peripheral vessels increase in diameter by such an amount during the first 4 months that some new muscle cells must have appeared during that time. At the hilum, on the other hand, it would seem that vessels lose muscle cells by atrophy (Hislop, 1971).

The later loss in muscle wall thickness in vessels over $200 \mu \mathrm{m}$ is not reflected in measured physiological changes but there is a drop in the muscularity of the right ventricle of the heart at this time. Loss of arterial muscle was shown to follow reduction in pressure and flow in children with a ventricular septal defect treated surgically by creation of a pulmonary stenosis (Dammann et al.. 1961). It may be that there are two types of muscle in the pulmonary arteries, one reacting to humoral agents by dilatation and a second type whose multiplication is reduced because of a drop in pressure and is also related to heart growth.

We should like to thank Professor K. Simpson and Professor D. Teare for their help. This study was supported by the Research Committee of the Board of Governors of the Brompton Hospital and is part of the work accepted for the degree of Ph.D. London University. Dr. Hislop is currently supported by the British Heart Foundation.

\section{REFERENCES}

Adams, F. H. (1966). Functional development of the fetal lung. J. Pediat., 68, 794.

Bergofsky, E. H., Lehr, D. E., and Fishman, A. P. (1962). The effect of changes in hydrogen ion concentration on the pulmonary circulation. J. clin. Invest., 41, 1492.

Boyden, E. A. (1965). The terminal air sacs and their blood supply in a 37-day infant lung. Amer.J. Anat., 116, 413. , and Tompsett, D. H. (1965). The changing patterns in the developing lungs of infants. Acta anat., (Basel). 61, 164.

Bucher, U., and Reid, L. (1961). Development of the intrasegmental bronchial tree: the pattern of branching and development of cartilage at various stages of intrauterine life. Thorax, 16, 207.

Burton, A. C. (1959). The relation between pressure and flow in the pulmonary bed. In: Pulmonary Circulation, edited by W. R. Adams and I. Veith, pp. 26-35. Grune and Stratton, New York. 
Dammann, J. F., McEachen, J. A., Thompson, W. M., Smith, R., and Muller, W. H. (1961). The regression of pulmonary vascular disease after the creation of pulmonary stenosis. J. thorac. cardiovasc. Surg., 42, 722.

Davies, G. M. (1969). The effect of chronic lung disease in childhood on lung growth, including measurement of right ventricular weight, alveolar development and pulmonary artery structure. M.D. thesis, University of Cambridge.

monary arteries in childhood. Thorax, 25, 669.

Dawes, G. S., Mott, J. C., Widdicombe, J. G., and Wyatt, D. G. (1953). Changes in the lungs of the newborn lamb. J. Physiol. (Lond.), 121, 141.

Dunnill, M. S. (1962). Postnatal growth of the lung. Thorax, $17,329$.

Elliott, F. M. (1964). The pulmonary artery system in normal and diseased lungs-structure in relation to pattern of branching. Ph.D. thesis, University of London.

- and Reid, L. (1965). Some new facts about the pulmonary artery and its branching pattern. Clin. Radiol., 16, 193.

von Euler, U. S., and Liljestrand, G. (1946). Observations on the pulmonary arterial blood pressure in the cat. Acta physiol. scand., 12, 301.

Hilton, S. M. (1959). A peripheral arterial conducting mechanism underlying dilatation of the femoral artery and concerned in functional vasodilatation in skeletal muscle. J. Physiol. (Lond.), 149, 93.

Hislop, A. (1971). The fetal and childhood development of the pulmonary circulation and its disturbance in certain types of congenital heart disease. Ph.D. thesis, University of London.

, and Reid, L. (1970). New pathological findings in emphysema of childhood: 1. Polyalveolar lobe with emphysema. Thorax, 25, 682.
- , and - (1972a). Intrapulmonary arterial development during fetal life-branching pattern and structure. J. Anat., 113, 35.

- and - (1972b). Weight of the left and right ventricle of the heart during fetal life. J. clin. Path., 25, 534.

Kato, M., Staub, N. C. (1966). Response of small pulmonary arteries to unilobar hypoxia and hypercapnia. Circulat. Res., 19, 426.

Larroche, J. C., Nodot, A., and Minkowski, A. (1959). Développement des artères et artérioles pulmonaires de la période foetale à la période néonatale. Biol. Neonat. (Basel), 1, 37.

Melmon, K. L., Cline, M. J., Hughes, T., and Nies, A. S. (1968). Kinins: possible mediators of neonatal circulatory changes in man. J. clin. Invest., 47, 1295.

Naeye, R. L. (1961). Arterial changes during the perinatal period. Arch. Path., 71, 121.

- (1966). Development of systemic and pulmonary arteries from birth through early childhood. Biol. Neonat. (Basel), 10, 7 .

Pump, K. K. (1961). The circulation of the primary lobule of the lung. Dis. Chest, 39, 614 .

Reid, J. A., and Heard, B. E. (1963). The capillary network of normal and emphysematous human lungs studied by injections of Indian ink. Thorax, 18, 201.

Rowe, R. D., and James, L. S. (1957). The normal pulmonary arterial pressure during the first year of life. J. Pediat., 51, 1.

Staub, N. C. (1961). Gas exchange vessels in the cat lung (abstract). Fed. Proc., 20, 107.

Wagenvoort, C. A., and Wagenvoort, N. (1965). Age changes in muscular pulmonary arteries. Arch. Path., 79, 524. 